\title{
Operational Customer Relationship Management Pada Sari Good Bakery
}

\author{
Ghani Aziz'; ${ }^{1}$ Leonardi Paris Hasugian ${ }^{2}$ \\ ${ }^{1}$ Departemen Teknik dan Ilmu Komputer, Universitas Komputer Indonesia, Indonesia \\ ${ }^{2}$ Departemen Teknik dan Ilmu Komputer, Universitas Komputer Indonesia, Indonesia \\ ghani.aziz@hotmail.com
}

\begin{abstract}
Current customer service at Sari Good Bakery is still done simply. Product promotion is done by placing banners on their store, then doing promotion by word of mouth so that products tend to be only known by the people around the store and the promotion tend to flow slowly. Then to deliver customer comments through face to face directly or by telephone or SMS. This method sometimes results in forgotten comments due to unavailability of facilities to accommodate these comments so it has potential of customers decreases. The solution to overcome this problem is by building Operational Customer Relationship Management. The method used in this research is a descriptive qualitative method by doing interviews and observations. This Operational CRM uses the Object Oriented Programming approach and uses prototype development methods. Operational CRM that is built can improve customer service such as conducting promotions widely and storing feedback on the website.
\end{abstract}

Keywords: Customer service, Operational CRM, Website.

\begin{abstract}
ABSTRAK
Pelayanan pelanggan yang berjalan pada Sari Good Bakery masih dilakukan secara sederhana. Promosi produk dilakukan dengan pemasangan spanduk pada toko mereka, kemudian melakukan promosi dari mulut ke mulut sehingga produk cenderung hanya dikenal oleh masyarakat di sekitar toko dan penyampaian promosi cenderung mengalir dengan lambat. Lalu penyampaian komentar pelanggan mengenai pelayanan dan produk melalui tatap muka langsung maupun melalui telepon atau SMS. Cara pelayanan tersebut terkadang berakibat terlupakannya komentar dikarenakan belum tersedianya fasilitas untuk menampung komentar tersebut sehingga berpotensi mengalami berkurangnya pelanggan. Solusi untuk mengatasi masalah tersebut yaitu dengan membangun Operational Customer Relationship Management. Metode penelitian yang digunakan yaitu metode penelitian deskriptif kualitatif dengan melakukan wawancara dan observasi. Operational CRM ini menggunakan metode pendekatan Object Oriented Programming dan menggunakan metode pengembangan prototype. Operational CRM yang dibangun dapat meningkatkan pelayanan pelanggan seperti melakukan promosi secara luas dan menyimpan feedback pada situs web.
\end{abstract}

Kata kunci: Pelayanan pelanggan, Operational CRM, Situs web. 


\section{PENDAHULUAN}

Perusahaan-perusahaan berskala kecil hingga berskala besar yang ada saat ini terus mengalami perkembangan mengikuti perkembangan zaman. Perkembangan ini dirasa sangat cepat terjadi, terlebih lagi teknologi informasi juga turut berkembang dengan sangat cepat. Model bisnis pada perusahaan yang pada awalnya dilakukan dengan tanpa menggunakan bantuan perangkat komputer kini tidak sedikit perusahaan yang telah menjalankan bisnis dengan memanfaatkan teknologi yang terus berkembang dari bermacam-macam perangkat komputer yang ada pada saat ini. Hal ini dilakukan demi memenangkan persaingan antar perusahaan yang terjadi dengan sangat ketat.

Sari Good Bakery merupakan perusahaan yang bergerak dalam bidang produksi dan penjualan makanan. Produk utama mereka adalah roti. Adapun produk yang mereka tawarkan yaitu roti keju, roti pizza, roti manis, roti tawar pandan, roti tawar bantal, roti sehat pandan, roti sehat tawar, roti sehat gandum, roti wijen, roti kadet, roti kasino rege, roti buaya, dan kue ulang tahun. Varian produk tersebut bertahan hingga saat ini. Semakin bertambahnya perusahaan lain yang juga memiliki produk utama yang serupa dengan Sari Good Bakery tentu menimbulkan suatu persaingan antar perusahaan di bidang tersebut. Setiap perusahaan terus meningkatkan kualitas, berinovasi, hingga terus menekan harga jual demi merebut kepercayaan pelanggan terhadap perusahaan. Permasalahan yang terjadi saat ini adalah strategi apa yang harus digunakan perusahaan agar dapat merebut pasar untuk mendapatkan pelanggan dan memelihara hubungan dengan pelanggan tersebut dalam jangka waktu yang panjang. Salah satu strategi yang dapat menjadi solusi permasalahan tersebut adalah mengubah paradigma bisnis menjadi perusahaan yang berorientasi kepada pelanggan dengan menerapkan Operational CRM (Customer Relationship Management).

Operational CRM adalah salah satu dari tiga tipe aplikasi CRM (Operational CRM, Analytical CRM, dan Collaborative CRM) yang mana merupakan suatu metode yang digunakan oleh perusahaan untuk mengelola hubungan perusahaan dengan para pelanggannya. Fokus Operational CRM adalah pada otomatisasi dan peningkatan pada pelayanan terhadap pelanggan. Otomatisasi yang dimaksud mencakup otomatisasi penjualan, otomatisasi pemasaran, dan otomatisasi pelayanan. Adapun tujuan utama dari Operational CRM yaitu melakukan suatu promosi untuk menarik minat pelanggan baru, mendapatkan kontak dari pelanggan baru tersebut, kemudian mendapatkan semua hal mengenai apa yang diinginkan oleh pelanggan tersebut demi tercapainya pelayanan yang baik di seluruh siklus hidup pelanggan. Oleh karena itu, penerapan Operational CRM pada suatu perusahaan dirasa sangat penting untuk menarik minat pelanggan, kemudian mempertahankan pelanggan yang ada agar tetap loyal pada jasa atau produk yang ditawarkan oleh perusahaan tersebut. Hal ini diyakini karena dengan memanfaatkan Operational CRM, perusahaan akan mengetahui apa yang diinginkan dan diperlukan pelanggannya sehingga akan tercipta hubungan yang erat antara pelanggan dan perusahaan.

Sari Good Bakery telah memberikan pelayanan yang baik kepada pelanggannya. Tentu pelayanan tersebut ditujukan untuk membangun kemudian mempererat hubungan antara perusahaan dan pelanggan sehingga Sari Good Bakery dapat terus bersaing dengan perusahaan roti lainnya. Meski begitu, pelayanan yang saat ini dilakukan oleh Sari Good Bakery masih hanya sebatas melakukan promosi produk melalui pemasangan spanduk berisi informasi produk pada toko mereka, kemudian melakukan promosi dari mulut ke mulut sehingga produk cenderung hanya dikenal oleh masyarakat di sekitar toko dan penyampaian promosi cenderung mengalir dengan lambat. Lalu memberikan pelayanan yang baik dan mendengar komentar pelanggan mengenai pelayanan dan produk melalui tatap muka langsung maupun melalui telepon atau SMS (Short Message Service). Cara pelayanan tersebut terkadang berakibat terlupakannya komentar dikarenakan belum tersedianya fasilitas untuk menampung komentar tersebut sehingga berpotensi mengalami berkurangnya 
pelanggan.

Terdapat beberapa dasar acuan dari penelitian yang dilakukan oleh peneliti. Penelitian pertama yang menjadi acuan peneliti yaitu penelitian yang dilakukan oleh Ovi Dyantina, dkk. (2012) yang berjudul "Penerapan Customer Relationship Management (CRM) Berbasis Web (Studi Kasus Pada Sistem Informasi Pemasaran di Toko YEN-YEN)" yang menggunakan pendekatan terstruktur menjelaskan CRM yang diterapkan merupakan perangkat lunak berbasis web yang ditujukan untuk membantu pihak toko dalam meningkatkan kualitas pelayanan dan memudahkan pelanggan untuk memperoleh informasi produk dan layanan yang ditawarkan, melakukan pembelian produk, dan menyampaikan kritik dan saran beserta pertanyaan [1]. Perbedaan dari penelitian yang dilakukan oleh Ovi Dyantina, dkk. dengan penelitian ini adalah metode pendekatan yang digunakan pada penelitian yang dilakukan oleh Ovi Dyantina, dkk. menggunakan metode pendekatan terstruktur sedangkan metode pendekatan yang digunakan pada penelitian ini menggunakan metode pendekatan berorientasi objek.

Penelitian kedua yang menjadi acuan peneliti yaitu penelitian yang dilakukan oleh Adelia dan Jimmy Setiawan (2012) berjudul "Implementasi Customer Relationship Management (CRM) pada Sistem Reservasi Hotel berbasis Website dan Desktop" yang menggunakan pendekatan terstruktur menjelaskan CRM yang dibangun merupakan perangkat lunak untuk membantu pemilik hotel dalam meningkatkan layanan serta mempertahankan hubungan baik terhadap pelanggan. Pihak hotel dapat melakukan pengelolaan data master yang berupa data pelanggan/tamu, data kamar, data fasilitas, dan data makanan melalui aplikasi desktop. Pelanggan dapat mengakses informasi hotel serta pemesanan kamar melalui website yang disediakan. Fitur feedback dan rating juga disematkan pada perangkat lunak ini untuk mendapatkan komentar dan tingkat kepuasan dari para pelanggan mengenai fasilitas maupun pelayanan yang telah diberikan oleh pihak hotel. Tidak lupa juga pihak hotel menyimpan kontak e-mail para pelanggannya sehingga dapat memberikan penawaran/promo kepada pelanggannya di masa mendatang [2]. Perbedaan dari penelitian yang dilakukan oleh Adelia dan Jimmy Setiawan dengan penelitian ini adalah metode pendekatan yang digunakan pada penelitian yang dilakukan oleh Adelia dan Jimmy Setiawan menggunakan metode pendekatan terstruktur sedangkan metode pendekatan yang digunakan pada penelitian ini menggunakan metode pendekatan berorientasi objek. Basis data yang digunakan juga berbeda, pada penelitian yang dilakukan oleh Adelia dan Jimmy Setiawan menggunakan Microsoft SQL Server sedangkan pada penelitian ini menggunakan MySQL 10.1. Bahasa pemrograman yang digunakan juga berbeda, pada penelitian yang dilakukan oleh Adelia dan Jimmy Setiawan menggunakan C\# dan VB.NET sedangkan pada penelitian ini menggunakan PHP (Hypertext Preprocessor).

Agar pelayanan pada Sari Good Bakery dapat terus berjalan dengan baik dan optimal, maka perusahaan harus melakukan penerapan Operational CRM yang dapat melakukan promosi terhadap produk yang dijual oleh perusahaan kepada masyarakat luas melalui situs Sari Good Bakery, kemudian situs tersebut dapat menyimpan feedback dari pelanggan berupa rating dan hal apa saja yang membuat pelanggan merasa puas maupun tidak puas dari segi pelayanan maupun produk sehingga dapat membuat keputusan untuk meningkatkan loyalitas pelanggan dirasa penting untuk dilakukan demi menghadapi persaingan yang sudah pasti akan terus semakin ketat. Operational CRM ini menggunakan metode pendekatan Object Oriented Programming (OOP) dan menggunakan metode pengembangan prototype.

\section{METODE/PERANCANGAN PENELITIAN}

\subsection{Kajian Pustaka}

Menurut Jeperson, sistem informasi adalah suatu sistem pada suatu organisasi yang 
mempertemukan kebutuhan-kebutuhan pada organisasi tersebut kemudian menghasilkan laporan yang menjadi kebutuhan bagi pihak-pihak yang berhak pada sistem tersebut [3].

Menurut Brown dan Rigby, Reichheld, Dawson, Customer Relationship Management adalah suatu proses untuk memperoleh, mempertahankan, dan mengembangkan pelanggan yang berpotensi bagi perusahaan. CRM meningkatkan pelayanan yang diberikan kepada pelanggan sehingga pelanggan merasa mendapatkan nilai lebih dari pelayanan yang diberikan sehingga menimbulkan suatu loyalitas. Jadi, CRM merupakan suatu strategi bisnis yang memiliki tujuan memahami, mengantisipasi, serta me-manage hal-hal yang dibutuhkan pelanggan [4].

Operational CRM adalah salah satu dari tiga tipe aplikasi CRM (Operational CRM, Analytical CRM, dan Collaborative CRM) yang mana merupakan suatu metode yang digunakan oleh perusahaan untuk mengelola hubungan perusahaan dengan para pelanggannya. Fokus Operational CRM adalah pada otomatisasi dan peningkatan pada pelayanan terhadap pelanggan. Otomatisasi yang dimaksud mencakup otomatisasi penjualan, otomatisasi pemasaran, dan otomatisasi pelayanan [5]. Adapun tujuan utama dari Operational CRM yaitu melakukan suatu promosi untuk menarik minat pelanggan baru, mendapatkan kontak dari pelanggan baru tersebut, kemudian mendapatkan semua hal mengenai apa yang diinginkan oleh pelanggan tersebut demi tercapainya pelayanan yang baik di seluruh siklus hidup pelanggan.

Sugiyono mengungkapkan bahwa penelitian deskriptif merupakan suatu metode yang berfungsi untuk memberikan deskripsi atau gambaran terhadap suatu objek yang diteliti melalui data atau sampel yang telah dikumpulan dengan sebagaimana adanya. Sugiyono juga menjelaskan penelitian kualitatif sebagai metode penelitian yang berdasarkan pada filsafat postpositivisme, yang mana digunakan untuk melakukan penelitian pada kondisi objek secara alami, dimana peneliti berperan sebagai instrumen kunci, teknik pengumpulan data dengan triangulasi, analisis data yang bersifat induktif atau kualitatif, dan hasil dari penelitian kualitatif lebih menekankan kepada makna dibanding generalisasi [6]. Menurut Nana Syaodih Sukmadinata, penelitian deskriptif kualitatif ditujukan untuk memberikan deskripsi dan melakukan penggambaran berbagai kejadian yang terjadi secara alamiah maupun hasil perbuatan manusia, yang cenderung berfokus kepada karakteristik, kualitas, dan hubungan antar aktivitas tanpa memanipulasi kejadian tersebut [7].

Metode pendekatan Object Oriented Programming (OOP) merupakan metode yang diimplementasikan dengan pengorganisasian atas kerjasama dari sekumpulan objek, dimana objekobjek tersebut merupakan sebuah instance dari kelas dan kelas-kelas tersebut merupakan anggota dari hirarki yang direlasikan melalui pewarisan dari class utamanya [8]. Adapun alat bantu yang digunakan pada metode pendekatan Object Oriented Programming (OOP) adalah dengan menggunakan Unified Modelling Language (UML). UML adalah bahasa spesifikasi standar yang digunakan untuk melakukan dokumentasi, spesifikasi, dan membangun software. UML merupakan metodologi dalam mengembangkan suatu sistem yang berorientasi objek (OOP) dan juga merupakan alat untuk mendukung pengembangan sistem nantinya [9].

Pengembangan sistem model prototype merupakan pengembangan sistem yang menggunakan bentuk purwarupa/contoh yang mencakup sebagian ataupun sistem keseluruhan yang disampaikan kepada konsumen kemudian dikembangkan berdasarkan masukan dari konsumen agar tercapai produk akhir sesuai keinginan konsumen [10].

Black box testing atau juga disebut sebagai Behavioral Testing merupakan metode pengujian software dimana struktur internal atau desain dari software yang diuji tidak terlihat oleh penguji [11].

Use case diagram merupakan suatu pemodelan untuk kelakuan sistem informasi yang akan dibangun. Use case digunakan untuk mengetahui apa saja fungsi yang terdapat pada suatu sistem informasi serta siapa saja yang berhak menggunakan fungsi-fungsi tersebut [12]. 


\subsection{Metode Penelitian}

Penelitian ini menggunakan metode penelitian deskriptif kualitatif dengan melakukan wawancara dan observasi. Objek penelitian yang diteliti yaitu Sari Good Bakery yang beralamat di Jl. Mahar Martanegara Gg. Anggrek, Cimahi. Peneliti melakukan observasi pada pelayanan pelanggan di Sari Good Bakery. Peneliti juga melakukan wawancara kepada Bagian Administrasi. Peneliti mengajukan beberapa pertanyaan mengenai kegiatan promosi produk, kegiatan penyampaian komentar pelanggan mengenai pelayanan dan produk, dan kegiatan pemesanan roti dan kue khusus.

Peneliti menggunakan metode pendekatan OOP. Adapun alat bantu yang digunakan pada metode pendekatan OOP adalah dengan menggunakan UML.

Penelitian ini menggunakan metode pengembangan sistem model prototype. Pengembangan sistem model prototype ini dilakukan dengan hadirnya konsumen secara langsung sehingga konsumen dapat langsung mengevaluasi prototipe produk yang dihadirkan oleh pengembang untuk mencapai produk akhir yang sesuai dengan kebutuhan konsumen.

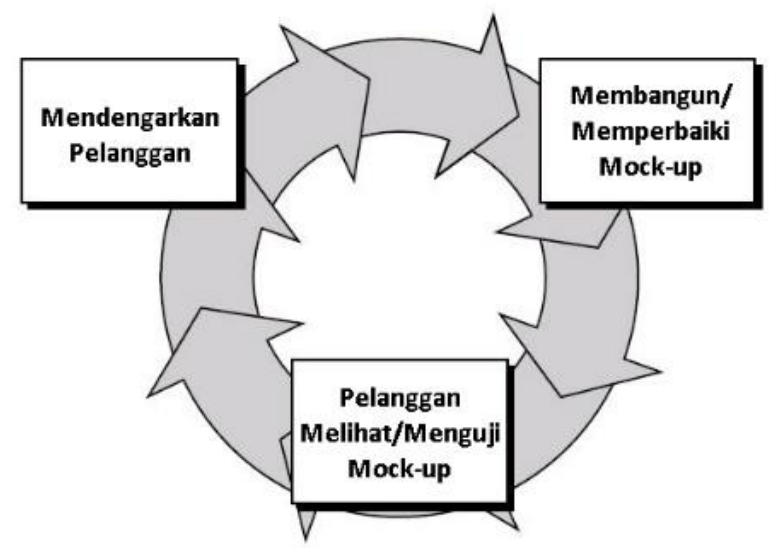

Gambar 1. Metode Pengembangan Sistem Model Prototype

Pengujian Software yang digunakan pada penelitian ini adalah black box testing untuk mengetahui perilaku software apakah telah sesuai dengan rancangan awal.

\section{HASIL DAN PEMBAHASAN}

\subsection{Gambaran Perancangan Sistem}

Sistem yang diusulkan menggunakan web untuk melakukan kegiatan promosi, menampilkan berbagai roti dan kue yang ditawarkan, memberikan dan menampung feedback, serta menangani pemesanan roti dan kue khusus. Laporan penjualan juga dihasilkan dan diakses melalui web ini sehingga menggantikan pelaporan penjualan sebelumnya yang berupa dokumen fisik.

Perancangan sistem Operational CRM pada Sari Good Bakery yang digambarkan menggunakan use case diagram disajikan pada gambar 2. 


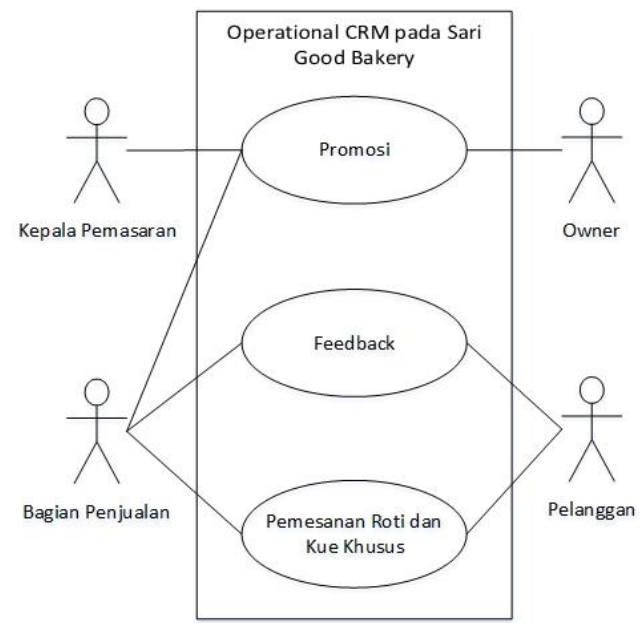

Gambar 2. Use Case Diagram

Berdasarkan use case diagram yang disajikan pada gambar 2, terlihat bahwa Operational CRM pada Sari Good Bakery memiliki 4 aktor yaitu Kepala Pemasaran, Owner, Bagian Penjualan, dan Pelanggan. Adapun deskripsi penjelasan dari setiap aktor disajikan pada tabel 1.

Tabel 1. Definisi Aktor dan Deskripsinya

\begin{tabular}{|c|l|l|}
\hline No & \multicolumn{1}{|c|}{ Aktor } & \multicolumn{1}{|c|}{ Deskripsi } \\
\hline 1. & $\begin{array}{l}\text { Kepala } \\
\text { Pemasaran }\end{array}$ & Pihak yang melakukan usulan promosi dalam bentuk apapun. \\
\hline 2. & Owner & $\begin{array}{l}\text { Pihak yang memutuskan layak tidaknya promosi untuk dipublikasi } \\
\text { serta melihat laporan. }\end{array}$ \\
\hline 3. & $\begin{array}{l}\text { Bagian } \\
\text { Penjualan }\end{array}$ & $\begin{array}{l}\text { Pihak yang memutuskan layak tidaknya feedback untuk } \\
\text { dipublikasi, menangani pemesanan roti dan kue khusus dari } \\
\text { Pelanggan, serta mengubah harga produk sesuai promosi yang } \\
\text { berlaku. }\end{array}$ \\
\hline 4. & Pelanggan & $\begin{array}{l}\text { Pihak yang menyampaikan feedback dan memesan roti dan kue } \\
\text { khusus. }\end{array}$ \\
\hline
\end{tabular}

Berdasarkan use case diagram yang disajikan pada gambar 1, juga terlihat bahwa Operational CRM pada Sari Good Bakery memiliki 3 use case yaitu Promosi, Feedback, dan Pemesanan Roti dan Kue Khusus. Adapun deskripsi penjelasan dari setiap use case disajikan pada tabel 2.

Tabel 2. Definisi Use Case dan Deskripsinya

\begin{tabular}{|c|l|l|}
\hline No & \multicolumn{1}{|c|}{ Use Case } & \multicolumn{1}{c|}{ Deskripsi } \\
\hline 1. & Promosi & $\begin{array}{l}\text { Proses dimana Kepala pemasaran melakukan usulan promosi } \\
\text { dalam bentuk apapun kepada Owner dan Owner memutuskan } \\
\text { layak tidaknya promosi untuk dipublikasi. Setelah promosi telah } \\
\text { disetujui dan berjalan, Bagian penjualan akan merubah harga } \\
\text { produk sesuai promosi yang berjalan kemudian promosi akan } \\
\text { dipublikasikan. }\end{array}$ \\
\hline 2. & Feedback & $\begin{array}{l}\text { Proses dimana Pelanggan menyampaikan feedback produk kepada } \\
\text { Bagian penjualan kemudian Bagian penjualan mengkonfirmasi } \\
\text { layak tidaknya feedback tersebut untuk dipublikasikan. }\end{array}$ \\
\hline
\end{tabular}




\begin{tabular}{|c|l|l|}
\hline 3. & $\begin{array}{l}\text { Pemesanan } \\
\text { Roti dan Kue } \\
\text { Khusus }\end{array}$ & $\begin{array}{l}\text { Proses dimana Pelanggan memesan roti dan kue khusus kepada } \\
\text { Bagian penjualan. }\end{array}$ \\
\hline
\end{tabular}

\subsection{Implementasi Perangkat Lunak}

Operational CRM pada Sari Good Bakery yang dirancang memiliki minimal spesifikasi perangkat lunak yang digunakan agar dapat bekerja secara optimal dan sesuai dengan yang dirancang. Adapun implementasi perangkat lunak yang digunakan pada Operational CRM pada Sari Good Bakery disajikan pada tabel 3.

Tabel 3. Implementasi Perangkat Lunak

\begin{tabular}{|l|l|}
\hline \multicolumn{1}{|c|}{ Perangkat Lunak } & \multicolumn{1}{c|}{ Spesifikasi } \\
\hline Sistem Operasi & Windows 7 32-bit \\
\hline Bahasa Pemrograman & PHP framework Codeigniter \\
\hline Web Server & Apache \\
\hline Database Server & MySQL \\
\hline Web Browser & Google Chrome / Mozilla Firefox \\
\hline Core Editor & Notepad++ \\
\hline
\end{tabular}

\subsection{Implementasi Perangkat Keras}

Sebuah aplikasi harus ditunjang oleh perangkat keras yang dapat mengoptimalkan kinerjanya sehingga aplikasi tersebut dapat berjalan dengan baik. Aplikasi Operational CRM pada Sari Good Bakery pun membutuhkan perangkat keras yang dapat mengoptimalkan kinerjanya. Oleh karena itu, minimal spesifikasi implementasi perangkat keras pada Operational CRM pada Sari Good Bakery disajikan pada tabel 4.

Tabel 4. Implementasi Perangkat Keras

\begin{tabular}{|l|l|}
\hline \multicolumn{1}{|c|}{ Perangkat Keras } & \multicolumn{1}{c|}{ Spesifikasi } \\
\hline Processor & Dual-Core Processor 2.4 GHz \\
\hline RAM & 2 GB \\
\hline VGA & NVIDIA GeForce GT 210 \\
\hline Harddisk & 128 GB \\
\hline Monitor & Monitor dengan resolusi HD (1366 x 768) \\
\hline
\end{tabular}

\subsection{Implementasi Antarmuka}

Setelah perancangan sistem, langkah selanjutnya yaitu melakukan implementasi antarmuka yang digunakan pengguna untuk berinteraksi dengan sistem untuk menjalankan berbagai kegiatan yang ada pada sistem informasi tersebut.

1) Implementasi Antarmuka Data Usulan Promosi

Implementasi antarmuka data usulan promosi digunakan untuk menampilkan semua data usulan promosi yang ada pada Operational CRM pada Sari Good Bakery. Tombol "Setuju" pada kolom konfirmasi berfungsi untuk menyetujui usulan promosi sedangkan tombol "Tolak" pada kolom konfirmasi berfungsi untuk menolak usulan promosi. Implementasi antarmuka data usulan promosi disajikan pada gambar 3 . 


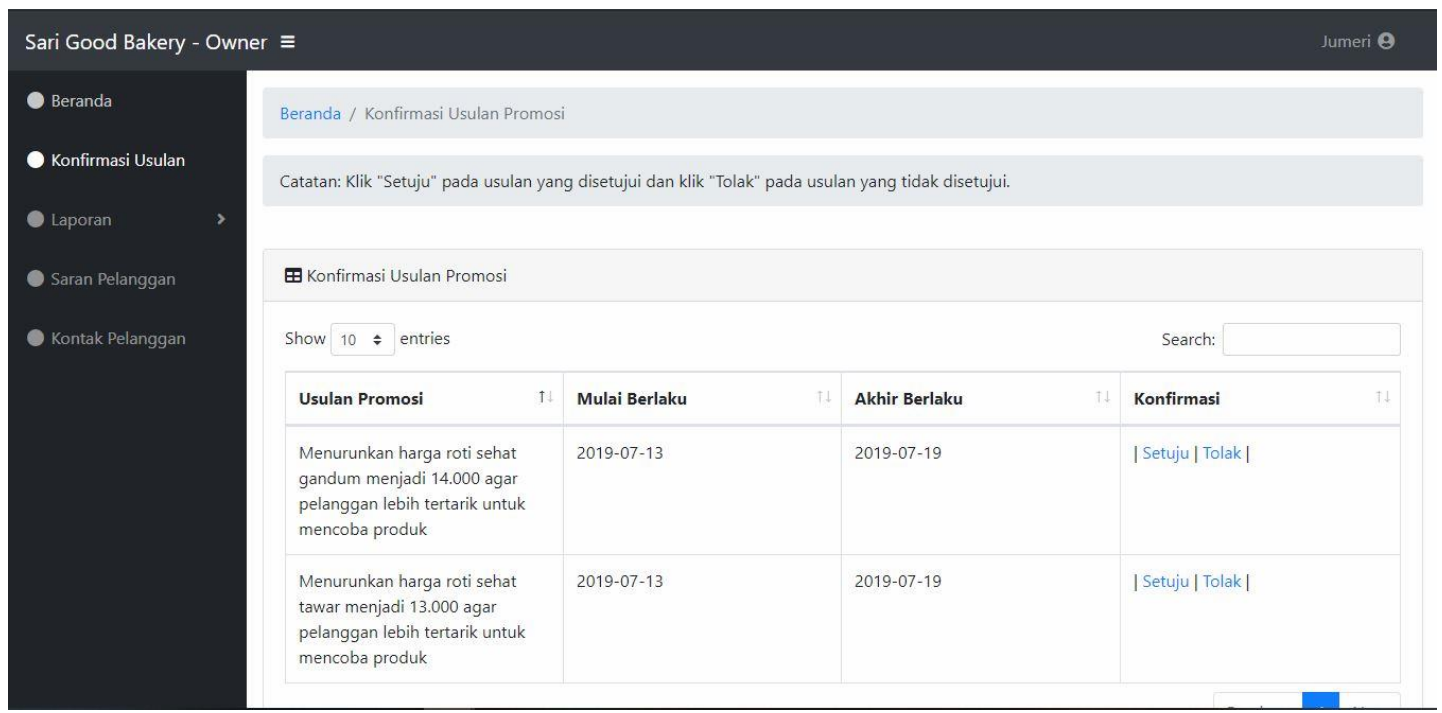

Gambar 3. Implementasi Antarmuka Data Usulan Promosi

2) Implementasi Antarmuka Data Feedback Produk

Implementasi antarmuka data feedback produk ini digunakan untuk menampilkan semua data feedback produk yang ada pada Operational CRM pada Sari Good Bakery. Tombol "Setuju" pada kolom konfirmasi berfungsi untuk menyetujui feedback produk untuk dipublikasi sedangkan tombol "Tolak" pada kolom konfirmasi berfungsi untuk menolak feedback produk untuk dipublikasi. Implementasi antarmuka data feedback produk disajikan pada gambar 4.

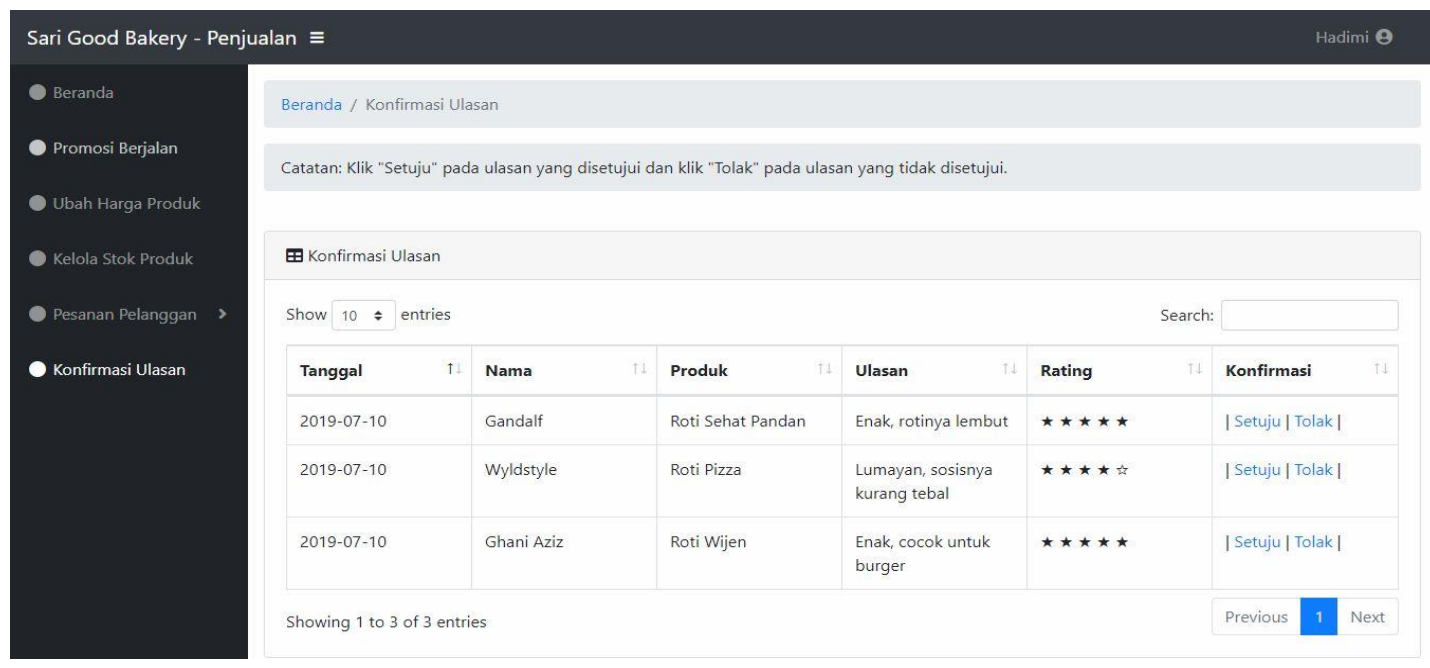

Gambar 4. Implementasi Antarmuka Data Feedback Produk

3) Implementasi Antarmuka Data Pesanan Roti dan Kue Khusus

Implementasi antarmuka data pesanan roti dan kue khusus ini digunakan untuk menampilkan semua data pesanan roti dan kue khusus yang ada pada Operational CRM pada Sari Good Bakery. Tombol "Proses" pada kolom konfirmasi berfungsi untuk memproses pesanan pelanggan untuk selanjutnya meminta pembayaran sedangkan tombol "Tolak" pada kolom konfirmasi berfungsi untuk menolak pesanan pelanggan. Implementasi antarmuka data pesanan roti dan kue khusus disajikan pada gambar 5. 


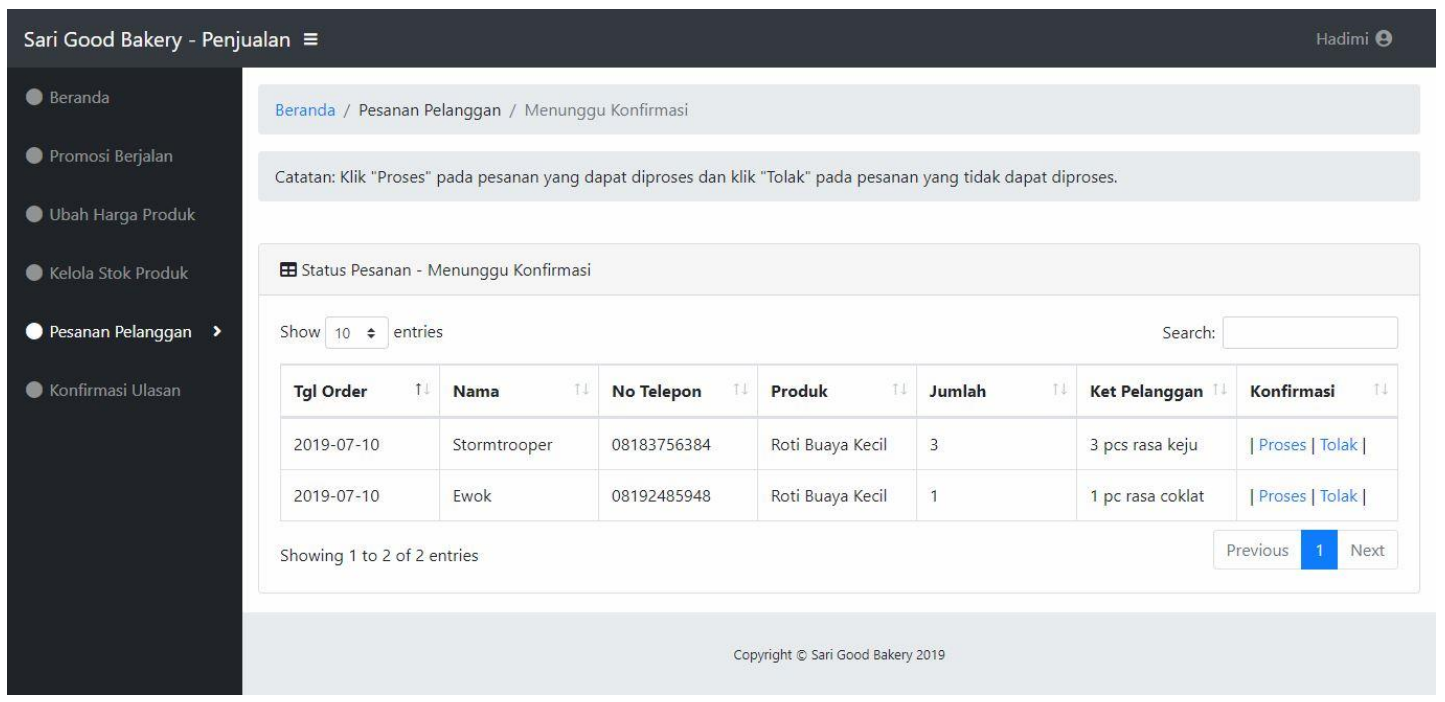

Gambar 5. Implementasi Antarmuka Data Pesanan Roti dan Kue Khusus

\section{KESIMPULAN DAN SARAN}

Berdasarkan penelitian yang telah dilakukan, peneliti menarik beberapa kesimpulan sebagai berikut: (1) Operational CRM yang dirancang dapat melakukan promosi produk kepada masyarakat luas melalui situs web. (2) Penyampaian komentar dari pelanggan mengenai produk maupun layanan yang diberikan oleh perusahaan dapat disampaikan dan ditampung pada situs web sehingga seluruh komentar dari pelanggan dapat tersimpan dan diakses dengan mudah.

Operational CRM pada Sari Good Bakery yang dirancang oleh peneliti ini masih memiliki banyak kekurangan. Oleh karena itu, peneliti mempunyai beberapa saran yang mungkin dapat dijadikan pengembangan dari penelitian ini apabila ada peneliti lain yang ingin menjadikan penelitian ini sebagai acuan kemudian melakukan pengembangan. Saran tersebut diantaranya: (1) Untuk mempermudah akses, Operational CRM ini dapat dikembangkan menjadi lintas platform seperti dibuat versi aplikasi Android maupun iOS. (2) Menambahkan fitur-fitur lanjutan dari fungsifungsi dasar yang sudah ada untuk semakin menambah nilai perusahaan di mata pelanggan.

\section{UCAPAN TERIMAKASIH}

Peneliti mengucapkan banyak terima kasih kepada dosen Program Studi Sistem Informasi Universitas Komputer Indonesia yang telah memberikan ilmu, memberikan teknik penyelesaian penelitian, memberikan pengarahan, serta memberikan dukungan yang membantu pelaksanaan penelitian serta penulisan artikel.

\section{DAFTAR PUSTAKA}

[1] Dyantina, O., Afrina, M., \& Ibrahim, A. (2012). Penerapan Customer Relationship Management (CRM) Berbasis Web (Studi Kasus Pada Sistem Informasi Pemasaran di Toko YEN-YEN). Jurnal Sistem Informasi (JSI) (Vol. 4, no. 2, pp. 516-529). Oktober, 2012. https://ejournal.unsri.ac.id/index.php/jsi/article/view/1274

[2] Adelia, \& Setiawan, J. (2011). Implementasi Customer Relationship Management (CRM) pada Sistem Reservasi Hotel Berbasis Website dan Desktop. Jurnal Sistem Informasi (Vol. 6, no. 2, pp. 113-126). http://jutisi.maranatha.edu/index.php/jusi/article/view/291

[3] Hutahaean, Jeperson. (2015). Konsep Sistem Informasi. Yogyakarta: Deepublish. 
[4] Munandar, Dadang. (2011). Customer Relationship Management Terhadap Loyalitas Pelanggan Bisnis PT. Frisian Flag Indonesia Bandung. Jurnal Majalah Ilmiah Unikom (Vol. 7, no. 1, pp. 137-148). https://jurnal.unikom.ac.id/jurnal/customer-relationship.m

[5] What is Operational CRM. [Online]. https://techonestop.com/what-is-operational-crm/.

[6] Sugiyono. (2012). Metode Penelitian Kuantitatif Kualitatif dan R\&D. Bandung: Alfabeta.

[7] Sukmadinata, N.S. (2011). Metode Penelitian Pendidikan. Bandung: PT Remaja Rosdakarya.

[8] Mulyani, Sri. (2016). Metode Analisis dan Perancangan Sistem. Bandung: Abdi Sistematika.

[9] Gata, W., \& Gata, G. (2013). Sukses Membangun Aplikasi Penjualan dengan Java. Jakarta: PT Elex Media Komputindo.

[10] Simarmata, Janner. (2010). Rekayasa Perangkat Lunak. Yogyakarta: Penerbit ANDI.

[11] Black Box Testing - Software Testing Fundamentals [Online]. http://softwaretestingfundamentals.com/black-box-testing/.

[12] Hendini, Ade. (2016). Pemodelan UML Sistem Informasi Monitoring Penjualan dan Stok Barang (Studi Kasus: Distro Zhezha Pontianak). Jurnal Khatulistiwa Informatika (Vol. 4, no. 2, pp.107-116). http://ejournal.bsi.ac.id/index.php/jki/article/view/78 